\title{
PHYSICAL CIRCULATION AND SPATIAL EXCHANGE DYNAMICS IN A SHALLOW FLOODPLAIN WETLAND
}

\author{
Z. SHARIP1,2,3, M.R. HIPSEY ${ }^{1,4}$, S.S. SCHOOLER ${ }^{5}$ \& R.J. HOBBS ${ }^{2}$ \\ ${ }^{1}$ Centre for Ecohydrology, School of Environmental Systems Engineering, University of Western Australia, Australia. \\ ${ }^{2}$ School of Plant Biology, University of Western Australia, Australia. \\ ${ }^{3}$ National Hydraulic Research Institute of Malaysia, Ministry of Natural Resources and Environment, Malaysia. \\ ${ }^{4}$ School of Earth and Environment, University of Western Australia, Australia. \\ ${ }^{5}$ Lake Superior National Estuarine Research Reserves, University of Wisconsin-Superior, USA.
}

\begin{abstract}
This paper examines the spatial patterns of water exchange based on water temperature variation between littoral and pelagic zones and compares the patterns in a series of shallow lakes at different water levels. Exchange patterns were assessed by developing isotherms along the transects and estimating the surface energy budget using the vertical temperature profile and time-series measurements. Our results indicate the presence of density-driven flow induced by the differential temperature gradient between littoral areas, which are dominated by either floating-leaved or submerged vegetation, and the open pelagic region. Persistent stratification was noted in the narrower lakes, which was thought to be due to the presence of dense submerged vegetation that attenuate wind-driven turbulence. In addition, variation of thermal stratification and mixing dynamics between these lakes at different water levels has corresponding effects on the biological and chemical regimes. The circulation contributes to increased transport of the phosphate that could favour submerged species and subsequently induce shifts of macrophyte community composition. The results of this study have implications for the rehabilitation and management of lake ecosystems.

Keywords: convective circulation, density driven flow, floating-leaved plant, Lake Chini, shallow wetland, submerged macrophytes, thermal stratification, water exchange.
\end{abstract}

\section{INTRODUCTION}

Convective circulation induced by density gradients resulting from horizontal depth variation has been demonstrated to be an important exchange mechanism of phosphorus [1,2] and mercury [3] between the littoral and pelagic zones, nutrients between side embayment and the main basin of reservoir [4], and pollutants between a fringing wetland and lake [5]. A temperature gradient develops when shallow littoral areas and deeper pelagic zones receive the same incoming solar radiation but distribute it differently over their respective volumes $[1,4,6,7]$. Several studies have also shown that aquatic plants are able to induce convective motion by promoting differential shading and by attenuating wind in shallower regions, which can further lead to horizontal and vertical gradients in temperature $[5,8-13]$.

Studies on the convective exchange between vegetated littoral regions and pelagic zones have been focused on emergent vegetation communities [5] such as reed beds [11,12] and Typha stands [13], and floating species such as Azolla sp. and Lemna sp. [8]. In all of these studies, a horizontal density gradient develops as the surface water underneath or within the vegetation becomes colder than the adjacent open water due to shading, and subsequently induces overflow of warmer pelagic water along the surface towards the plant bed during the day. The resulting horizontal temperature gradient induced by differential shading also differs with the density of the vegetation bed $[12,13]$.

From an ecological perspective, exchange flows generated by differential heating can contribute to replacement of nutrients taken up by the macrophytes [8]. However, despite the potential significance of this process in shaping the ecological dynamics of wetland macrophyte communities, studies on the effect of convective exchange induced by different types of macrophytes, for example 
rooted floating-leaved plants or submerged species, have been limited. In an earlier study, we identified differential nutrient gradients between the littoral and pelagic zones in Lake Chini, a tropical floodplain wetland in Malaysia [14], and it was hypothesized that this might have been influenced by temperature differences between the two zones and associated exchange between them. In particular, the circulation patterns induced by the thermal gradient could potentially regulate transport of nutrients to dense submerged beds of the highly invasive macrophyte, Cabomba furcata [14], and subsequently promote the proliferation of this species due to its ability to uptake nutrients through stems and shoots [15].

The aim of this study is to examine the convective exchange pattern resulting from differential cooling and heating in a shallow floodplain wetland and its effect on water quality dynamics in the system that could contribute to the shifts of macrophyte community composition that have been previously documented [14]. Specifically, we identify how horizontal exchange flows are affected by the dominance of two different types of aquatic plants along the littoral areas and also investigate the variation in the circulation pattern in two sub-basins in the wetland at different water levels. This is achieved by (1) describing the spatial and temporal variations in thermal structure, light climate and phosphate concentrations in the two lakes of the wetland system during low- and high water level or flooding, (2) estimating the surface energy budgets and the convective flow rates between the littoral zone and open water at two sites, and (3) using this information to assess the implications of physical-chemical coupling to macrophyte responses and the density gradient induced by differential shading by vegetation between the littoral and pelagic zones as an important mechanism for transport of nutrients to $C$. furcata beds, and subsequently the promotion of invasion of the species in the wetland system. This study also provides an improved understanding of the water circulation induced by differential heating and cooling in areas dominated by different types of aquatic plants, namely emergent floating leaved plants versus submerged macrophytes.

\section{METHODS}

\subsection{Study site}

Lake Chini, Malaysia is a shallow wetland located within the Pahang River floodplain, which exhibits characteristics of a system that suggest multiple ecological regime shifts driven by flood and nutrient delivery [14]. The wetland comprises a series of 12 inter-connected lakes, has a total surface area of $1.69 \mathrm{~km}^{2}$ and an average depth of $1.9 \mathrm{~m} \mathrm{[16],} \mathrm{with} \mathrm{its} \mathrm{littoral} \mathrm{areas} \mathrm{extensively} \mathrm{dominated}$ either by stands of the floating-leaved plant (Nelumbo nucifera) or submerged species (C. furcata). To maintain water level for year-round navigability, a weir was constructed at the downstream end of Chini River in 1995, which connects the wetland with the main river [16, 17].

\subsection{Field measurements}

Surveys were carried out from 19th to 24th April 2010 to investigate the exchange flows between the littoral and pelagic regions. Transects were positioned in two lakes; Lake 1 linking the open pelagic region to littoral area dominated by floating-leaved vegetation, and Lake 12 linking the pelagic zone to a littoral area dominated by submerged vegetation (Fig. 1).

Thermistor chains were deployed at two locations within the pelagic zone (Stations 3 and 4) in Lake 1 and Lake 12 and at one location in Lake 5; each anchored at the top on buoy and kept taut to the bottom by a weight. The three sites were selected to represent lakes dominated either by $N$. nucifera (Lake 1), or by $C$. furcata (Lake 12) and by both species and subjected to direct flooding 


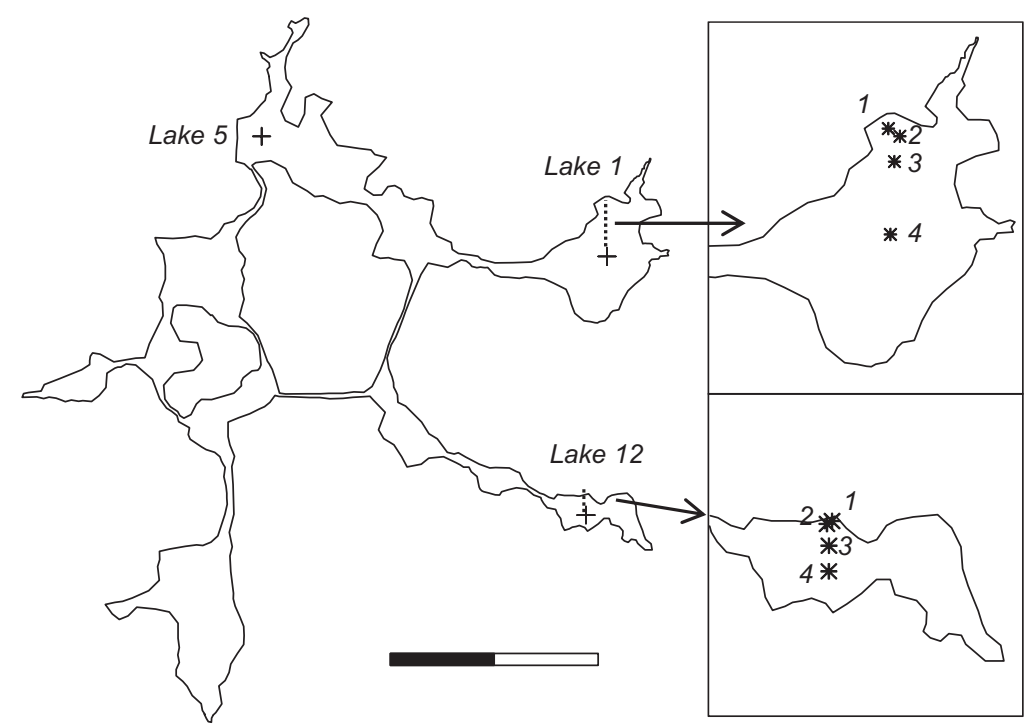

Figure 1: Lake Chini and the location of temperature monitors along the transects (inset).

Table 1: Temperature monitors in Lake Chini.

\begin{tabular}{llrlr}
\hline Sensor & Parameter & $\begin{array}{c}\text { Recording interval } \\
(\mathrm{min})\end{array}$ & Depth $(\mathrm{m})$ & Lake \\
\hline Hobo & Temperature & 15 & $0.5,1.0,2.0$ & $1,5,12$ \\
RBR & Temperature & 1 & 1.0 & 1,12 \\
D-Opto & Temperature, DO & 1 & 0.5 & 1,12 \\
TPS sensors & Temperature, DO & $10-20$ & $0.15-0.25$ & 1,12 \\
Hydrolab & Temperature, DO, & 15 & 1.0 & 1,12 \\
& pH, Chlorophyll & & & \\
\hline
\end{tabular}

due to its close proximity to the weir (Lake 5). Four TPS WP82 temperature-dissolved oxygen sensors (TPS Pty Ltd, Brisbane, Australia) were deployed at the littoral zone; one sensor was deployed at the open water near the edge of the macrophyte bed at approximately 0.2-m depth (Station 2), and another three sensors inserted at the top of benthic chambers (Station 1) with a $12 \mathrm{~V}$ submersible pump used to re-circulate the water within the chamber to maintain similar water conditions as outside. Thermistors recorded temperatures at intervals and depth as shown in Table 1. Vertical profiles of photosynthetically active radiation (PAR) and temperature/depth were made with a LiCOR sensor (Li-192SA) and a YSI 6600 multi-parameter profiler. The temperature sensors were calibrated together in a container at varying temperatures, either before or after field experiments. Temperature data were corrected where necessary with the mean temperature so that the maximum differences between any loggers do not exceed $0.15^{\circ} \mathrm{C}$. Linear interpolation was used to calculate hourly interval values where necessary. Water samples were collected at surface- and bottom levels at each lake for analysis of phosphate, nitrate and dissolved organic carbon in accordance with standard methods (APHA 1992). Additional vertical profiles of temperature and light were also carried out using a 
YSI 6600 multi-parameter probe and a LICOR sensor on 29 and 30th March 2011 during a high water level period. The profiling was carried out around mid-noon and early morning where differential heating and differential cooling would likely to occur [18].

Hourly meteorological data were obtained from a weather station positioned in the centre of Lake 1, and the Muadzam Shah Meteorological Station located about $40 \mathrm{~km}$ south of the study site. The on-lake weather station recorded solar radiation, wind speed, air temperature, relative humidity and precipitation. Due to the failure of the wind speed and air temperature sensors, the wind speed and air temperature data were collected from the Muadzam Shah Station. To include the localized lake effect, air temperature and wind speed values at the lake were calculated from the Muadzam Shah Station using a linear regression between data from the two sites at times when both were available. The air temperature and wind speed data between the on-lake weather station and Muadzam Shah meteorological station were highly correlated $\left(r^{2}=0.87, n=2880, p<0.001\right.$ and $\left.r^{2}=0.53, n=356, p<0.001\right)$. Mean air temperature at Lake Chini $\left(26^{\circ} \mathrm{C}\right)$ was significantly lower by $4.5 \%(\mathrm{t}=15.1, \mathrm{~d} f=5338.5$, $\mathrm{p}<0.001)$ than mean air temperature at the Muadzam Shah Station, and this could be due to microclimatic differences caused by the surrounding topography and the mediating effect of the water body.

\subsection{Analysis of physical-chemical structure and heat budget calculations}

Spatial distribution of water temperature and the phosphate concentrations were generated along the transects using SURFER (version 9.0; Golden Software, Inc.) with kriging as the gridding method. Convective exchange patterns were assessed by generating contours over the transects using the temperature data recorded by thermistor probes and temperature/depth profile data measured over 45-min intervals or less as described in [18].

The atmospheric heat flux calculations were computed in Matlab R2008a (The MathWorks) using a bulk aerodynamic approach applied to the available meteorological data [19-21]. The two lakes were assumed to have similar meteorological parameters. The overall heat budget calculation was calculated according to Lovstedt et al. [12]:

$$
\rho_{0} C_{P} \int_{0}^{h} \frac{\partial T}{\partial t} \partial Z=R_{n e t}-H_{\text {Latent }}-H_{\text {sensible }}+H_{Q} .
$$

where, $\rho_{0}$ is the density of water $\left(\mathrm{kg} / \mathrm{m}^{3}\right), \mathrm{C}_{\mathrm{p}}$ is the specific heat capacity for water, $4.18 \times 10^{3} \mathrm{~J} /$ $(\mathrm{kg} \mathrm{K}), \mathrm{h}$ is the water depth $(\mathrm{m}), \partial \mathrm{T}$ is the average temperature change $\left({ }^{\circ} \mathrm{C}\right)$ over the time step, $\partial \mathrm{t}(\mathrm{s})$, $\mathrm{z}$ is the vertical distance from surface $(\mathrm{m}), \mathrm{H}_{\text {latent }}$ is the heat loss by latent heat fluxes $\left(\mathrm{W} / \mathrm{m}^{2}\right), \mathrm{H}_{\text {sensible }}$ is heat loss by sensible heat transfer $\left(\mathrm{W} / \mathrm{m}^{2}\right)$ and $\mathrm{H}_{\mathrm{Q}}$ is the lateral heat flux between the open water and the vegetation bed. The incoming net solar radiation, $\mathrm{R}_{\mathrm{net}}\left(\mathrm{W} / \mathrm{m}^{2}\right)$, was calculated according to:

$$
R_{\text {net }}=H_{\text {shortwave }}+H_{\text {longwave }}-H_{\text {backradiation }} \text {. }
$$

where the short wave radiation was estimated as:

$$
H_{\text {shortwave }}=(1-\alpha) S_{\text {in }} \text {. }
$$

Here $S_{\text {in }}$ is the short wave incoming radiation $\left(\mathrm{W} / \mathrm{m}^{2}\right), \alpha$ is the albedo or the reflectance of the solar radiation and was taken as 0.05 from water surface [22] and 0.16 from the floating-leaved, water lily [23]. The incoming long wave radiation and the long wave back radiation were calculated according to:

$$
H_{\text {longwave }}=\varepsilon_{a}\left(1+0.17 C^{2}\right) \varepsilon_{w} \sigma T_{a}^{4} .
$$




$$
\begin{aligned}
& \varepsilon_{a}=0.642\left(e_{a} / \mathrm{T}_{a}\right)^{1 / 7} . \\
& H_{\text {backradiation }}=\varepsilon \sigma T_{w}{ }^{4} .
\end{aligned}
$$

where $\sigma$ is the Stefan-Boltzmann constant $\left(=5.67 \times 10^{-8} \mathrm{~W}^{\circ} \mathrm{K}^{-4} \mathrm{~m}^{-2}\right), \varepsilon_{\mathrm{a}}$ is emissivity of air, $\mathrm{e}_{\mathrm{a}}$ is the vapour pressure of the air $(\mathrm{Pa}), \mathrm{C}$ is the fraction of cloud cover, $\mathrm{T}_{\mathrm{a}}$ is the air temperature $\left({ }^{\circ} \mathrm{K}\right), \mathrm{T}_{\mathrm{w}}$ is the surface water temperature $\left({ }^{\circ} \mathrm{K}\right)$ and $\varepsilon$ is the surface emissivity $(=0.97$ for water $[22]$ and $=0.98$ for the aquatic plant vegetation [12]).

The sensible and latent heat fluxes, $\mathrm{H}_{\text {sensible }}$ and $\mathrm{H}_{\text {latent }}$, were estimated using the bulk aerodynamic transfer method based on the wind speed and specific humidity gradient. To address the strong effect of the thermal inertia of the water over the dial scales [19], neutral values of the transfer coefficients at $10 \mathrm{~m}, \mathrm{C}_{\mathrm{DN}}=1.0 \times 10^{-3}, \mathrm{C}_{\mathrm{HN}}=1.35 \times 10^{-3}$ and $\mathrm{C}_{\mathrm{EN}}=1.35 \times 10^{-3}$ [19], were corrected for non-neutral atmospheric stability effects at the relevant measurement height following the Monin-Obukhov similarity theory $[19,24]$. In this study, sensible heat transfer coefficient $\left(C_{H}\right)$ was assumed the same as latent heat transfer coefficient $\left(C_{E}\right)$ in keeping with the literature $[19,21,25]$. The roughness length for momentum was considered in the formulation of the stability functions for stable conditions [25] with a cut-off of stability parameter, $\left|\mathrm{zL}^{-1}\right|<15$ imposed following the limits set in Imberger et al. [25]. The stability calculations were iterated until the Monin-Obukhov length scale (L), which is a ratio of the reduction of potential energy as a result of wind mixing and the development of atmospheric stratification due to the heat flux, converged to within $0.001 \%$ between iterations $[19,21]$.

The exchange flow, $\mathrm{Q}\left(\mathrm{m}^{3} \mathrm{~s}^{-1} \mathrm{~m}^{-1}\right)$ is derived from Lovstedt et al. [12]:

$$
H_{Q} . L=\rho_{0} C_{\mathrm{P}}\left(T_{\text {open }}-T_{\text {plant }}\right) Q .
$$

We assume the energy fluxes within the littoral bed were distributed evenly. To eliminate the influence of density gradient induced by depth variation, heat fluxes were calculated based on temperature measurements between Station 1 and Station 2 in each lake. The estimation of the heat fluxes covered the whole one-day cycle for Lake 1 and only the differential heating (day) phase in Lake 12 due to sensor failure. To check the reliability of the lateral heat flux estimation, the average temperature as a function of time was calculated at Station 2 using the atmospheric surface fluxes for the open water and lateral heat fluxes transported from Station 1, and compared with the measured temperature data (20-min interval) in the area [12].

The dissolved oxygen dynamic pattern will be described elsewhere. Vertical attenuation coefficients were calculated using the formula in Kirk [26] to evaluate light availability for submerged macrophytes. Analysis of means and T-Tests were performed in PASW Statistic 18 (SPSS Inc.).

\section{RESULTS}

\subsection{Meteorology and physical-chemical structure}

The weather during the April 2010 experiment was at its driest condition with no outflow as lake level was lower than the weir height. The skies were occasionally cloudy but no rainfall was recorded during the two days, thus inflows into the lakes were negligible. No information of groundwater was available to account for the temperature differences; however, this was thought to have a negligible influence. Wind speed was generally low during the days with an average wind speed of around $0.8 \mathrm{~m} / \mathrm{s}$. Wind speeds were near zero throughout the nights (Fig. 2a).

Air temperature cooled from a maximum of $30.4^{\circ} \mathrm{C}$ at $1600 \mathrm{~h}$ on 20 April to $23.7^{\circ} \mathrm{C}$ at $0600 \mathrm{~h}$ on 21 April (Fig. 2b). Air temperature was lower than the surface water temperature in both lakes, 

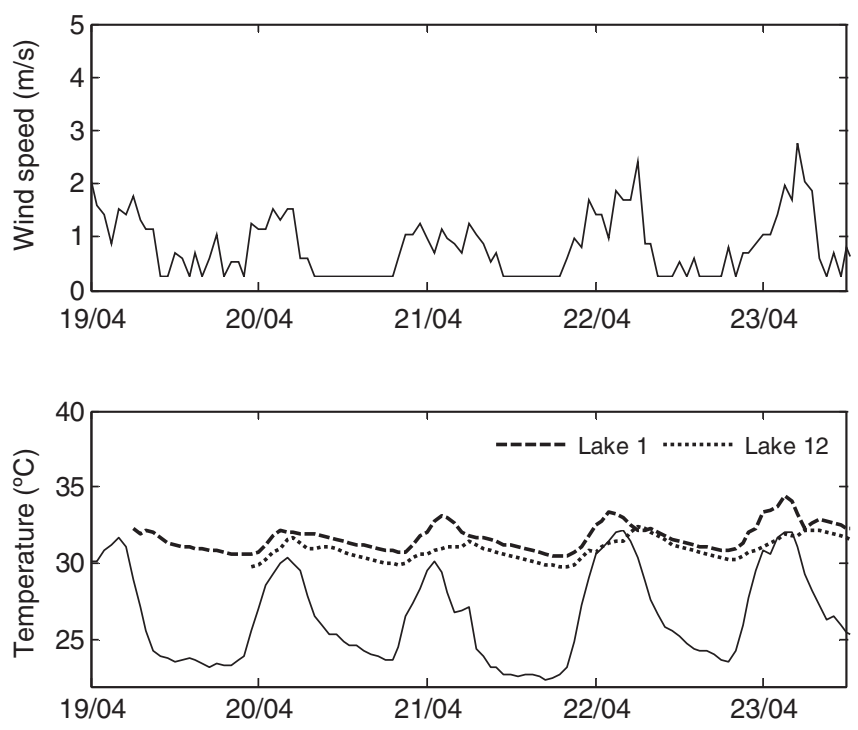

Figure 2: Variations in (a) wind speed (b) air temperature (thin line) and surface water temperature at Lake Chini during the experiment period in April 2010.

which has been frequently observed in tropical lakes and wetlands [19, 21, 27-29]. According to Verburg et al. [21], the lower air temperature than the surface water can cause an increase in atmospheric instability and subsequently an increase in sensible and latent heat loss and affect differential heating and cooling of the surface of the water.

High temperature within the littoral zone vegetation dominated by the floating-leaved plant, $N$. nucifera, was consistent with past studies [30]. The surface water temperature in the littoral area dominated by $N$. nucifera (Station 1) was $1.3^{\circ} \mathrm{C}$ warmer than the adjacent open water (Station 2), which could be due to sparse $N$. nucifera cover $(13 \%)$ in the area and shallower depth for heat absorption. Mean surface water temperatures were higher than the mean air temperature at the littoral and pelagic zones in both lakes $(\mathrm{p}<0.001)$. Mean temperature differences between the water-plant surface and the air were higher in the littoral zone of Lake 12 compared with Lake 1, with temperature values of 5.4 and $4.9^{\circ} \mathrm{C}$, respectively. Higher surface temperatures above submerged beds could be associated to absorption of solar radiation at the upper part of the water column. Differential heating during the day was apparent along both transects generating overflows from shallow littoral region to the pelagic zone as shown by the slanting contour in Fig. 3a and b. A weak metalimnion, as represented by the $31.8^{\circ} \mathrm{C}$ to $32.6^{\circ} \mathrm{C}$ contours, develop in Lake 1 at the pelagic region between the $0.5-$ and $1.0-\mathrm{m}$ depths. Around noon on 20th April, differential heating began to develop in Lake 12, as the water temperature at the littoral (Station 1) was nearly $2^{\circ} \mathrm{C}$ greater than those in the upper 0.5-m layer of the pelagic water at Station 4 (Fig. 3b).

The surface water temperature cooled more rapidly at the littoral site compared with the pelagic zone in both lakes during the night between 20 and 22 April 2010. Movement of cooler littoral water as an underflow current into the deeper pelagic zone is shown by the position of the $30.7^{\circ} \mathrm{C}$ isotherm (Fig. 3c). In Lake 12, the littoral area cooled sooner than the pelagic water which could be due to shading by the high-canopy forest where movement of cooler water starts to develop by late afternoon. Intrusion of cool water appeared to move away from the lake bed in Lake 12 as shown in the 

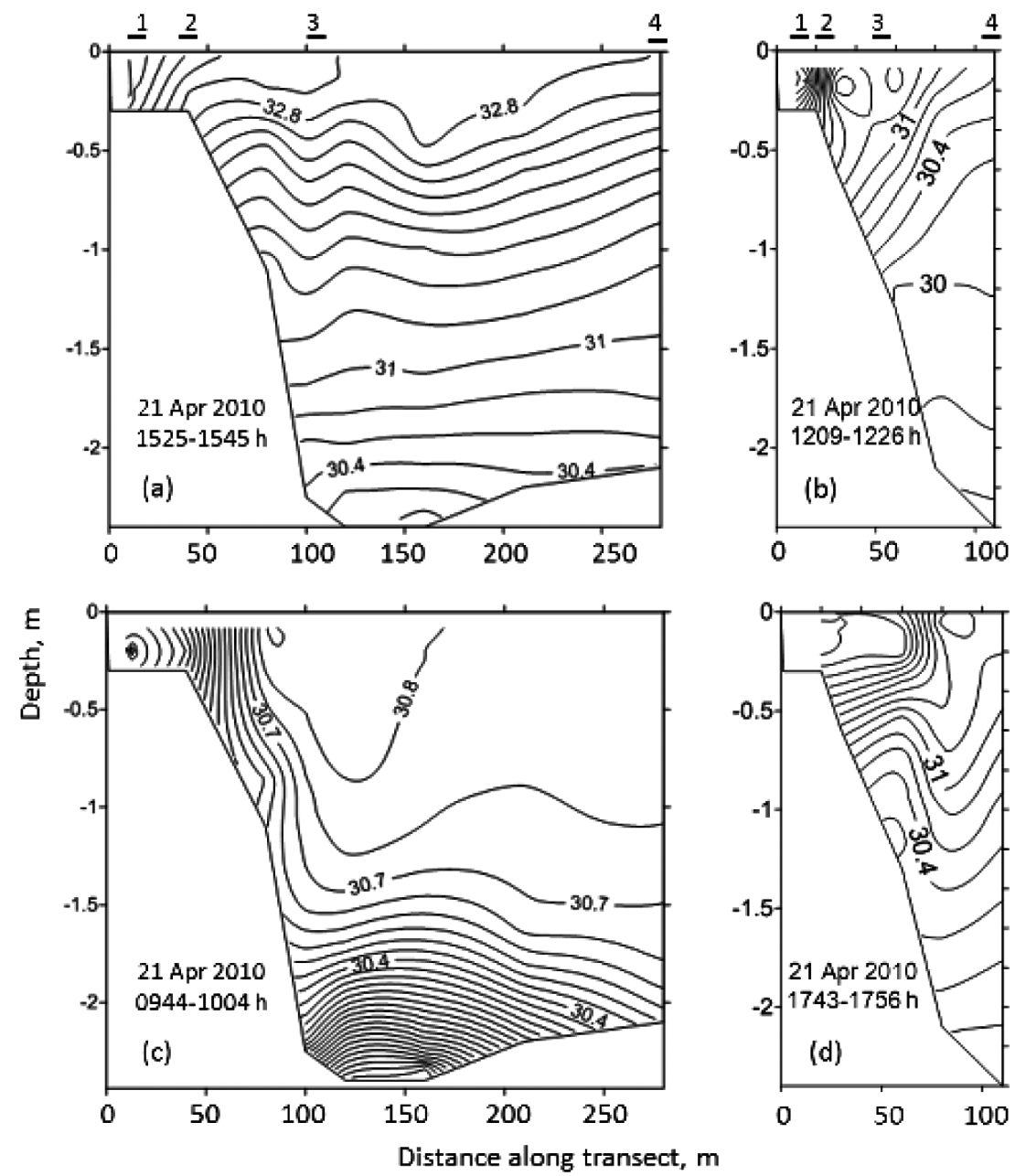

Figure 3: Longitudinal and vertical variations in water temperature on 21st April in (a) Lake 1 at around 1535, (b) Lake 12 at around 1220, (c) Lake 1 at around 0954, (d) Lake 12 at around 1750. Numbers and bars at top temperature profile correspond to station.

slanting contour at the surface (Fig. 3d), which could be associated with the presence of a dense monospecific submerged macrophyte bed (Station 3). The water at the surface and bottom layer also remained separated at Station 3 (Fig. 4c), which was in contrast to the pelagic zone (Station 4) (Fig. 4d) where the surface layer was completely mixed with the bottom layer.

Over the daily cycle, stratification and vertical mixing patterns were clearly different between the lakes (Fig. 5). A pattern of diurnal stratification during the day and complete mixing at night were apparent in Lake 1 and Lake 5, whereas stratification persisted in Lake 12, with the exception on the morning of 22 April, where the mixed layer did not reach $2 \mathrm{~m}$. As the magnitude of the wind stress was similar throughout the period, the lower solar radiation on the previous days (mean $=252.8 \mathrm{~W} / \mathrm{m}^{2}$ ) might have contributed to the deepening of the mixed layer depth to the 2-m layer. A similar phenomenon was described by MacIntyre et al. [31]. 

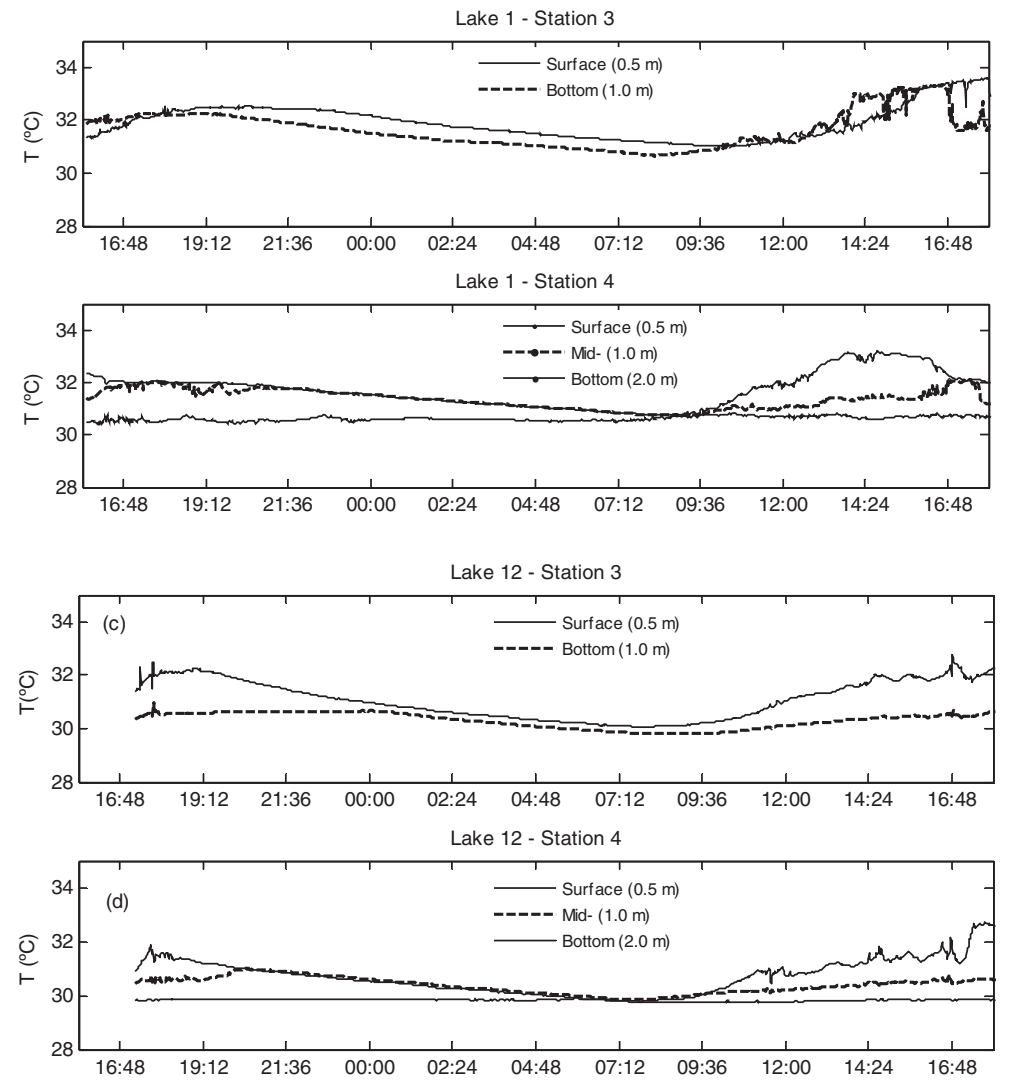

Figure 4: Variation in water temperature between the littoral zone and pelagic zone during 20-21 April 2010 (Lake 1) and 21-22 April 2010 (Lake 12).

In contrast to the thermal structure during low water level, a distinct pattern of stratification was observed in both Lake 1 and Lake 12 during a high water level (Fig. 6). Stratification persisted in Lake 1 with heat being entrained at the upper layer above the $1.5-\mathrm{m}$ depth causing strong metalimnion to develop between the $0.5-\mathrm{m}$ and $1.5-\mathrm{m}$ depths (Fig. 6a). Heat loss during the night induces a cooler and denser surface temperature which led to the deepening of the surface mixed layer by morning as shown by the reference contour $\left(26^{\circ} \mathrm{C}\right)$ (Fig. 6b). Conversely, the temperature structure in Lake 12 indicates that the littoral area experienced isothermal mixing that induced differential temperature between the littoral zone and the pelagic zone and the subsequent intrusion of cold water into the stratified pelagic water (Fig. 6d). Shading by high-canopy forest along lake fringes could contribute to isothermal littoral temperature at the littoral zone. Steedman et al. [32] showed that riparian shading reduces the littoral water temperature and this can cause unstable density gradient to develop as dense cold water sinks to the bottom [33].

Differences in light penetration were apparent between the low- and high-water periods in both lakes $(\mathrm{p}<0.001)$. During low-water periods, PAR reached ca. $0 \mu \mathrm{ms}^{-1} \mathrm{~m}^{-2}$ near the bottom of the submerged stands (Station 3). As qualitatively observed in Lake 12, wind-driven motion was attenuated over the dense submerged $C$. furcata stand where its shoots and floating leaves covering the surface water. The vertical attenuation coefficient, $\mathrm{K}_{\mathrm{d}}(\mathrm{PAR})$ in Lake $12\left(\mathrm{~K}_{\mathrm{d}}=1.54 \mathrm{~m}^{-1}\right)$ was not 

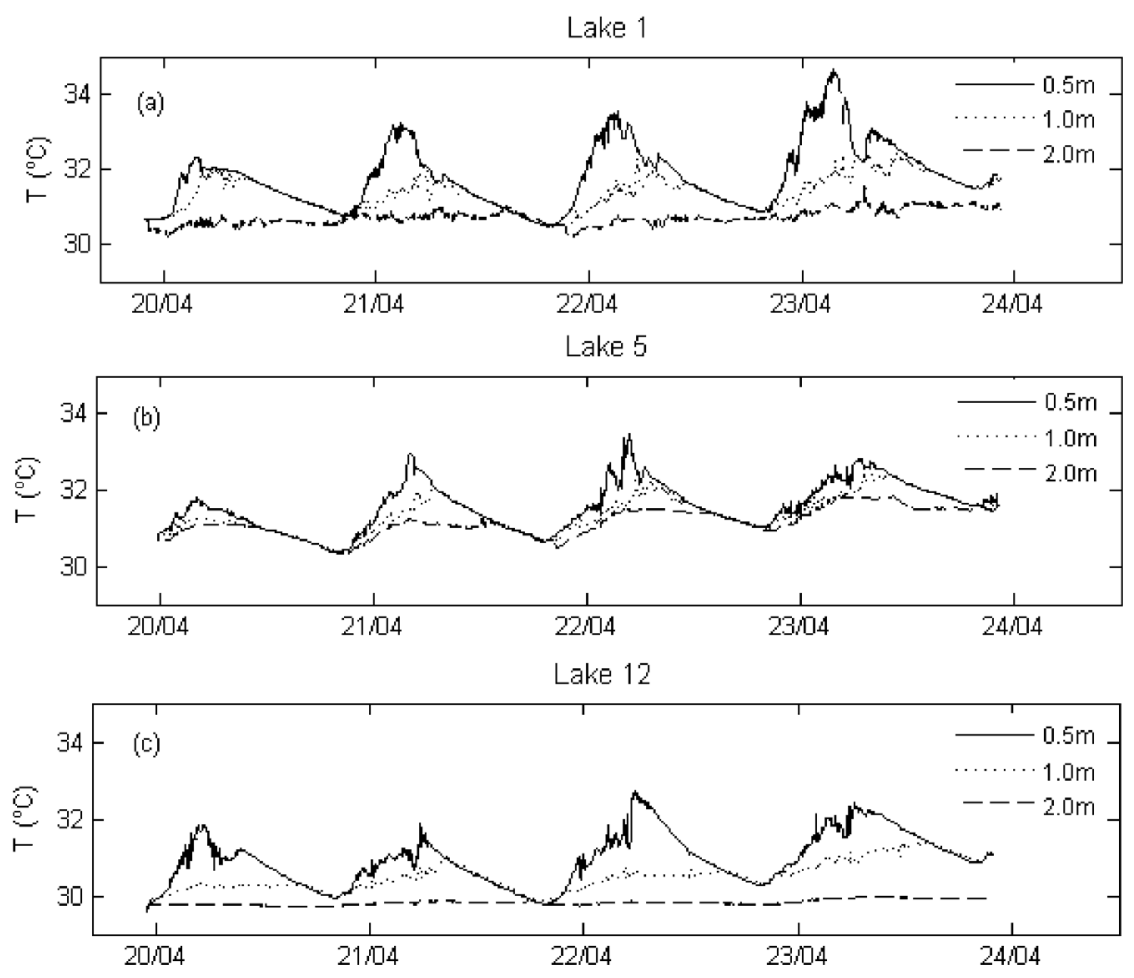

Figure 5: Thermistor time series at the pelagic zone, at (a) Lake 1 (b) Lake 5 and (c) Lake 12 between 20 and 24 April 2010.

statistically higher $(\mathrm{p}>0.01)$ than in Lake $1\left(\mathrm{~K}_{\mathrm{d}}=1.47 \mathrm{~m}^{-1}\right)$ during this period, which in contrast to a high water period where $\mathrm{K}_{\mathrm{d}}(\mathrm{PAR})$ in Lake $1\left(\mathrm{~K}_{\mathrm{d}}=2.92 \mathrm{~m}^{-1}\right)$ was significantly higher $(\mathrm{p}<0.001)$ than in Lake $12\left(\mathrm{~K}_{\mathrm{d}}=1.61 \mathrm{~m}^{-1}\right)$. Higher $\mathrm{K}_{\mathrm{d}}(\mathrm{PAR})$ in Lake 12 during a low water level could be attributed to humic substances generated by decomposition of plant matter [26]. This is consistent with mean DOC concentrations which were higher in Lake $12(74.6 \pm 5.7 \mathrm{mg} / \mathrm{L})$ compared with those of Lake $1(33.8 \pm 25.5 \mathrm{mg} / \mathrm{L})$. The direct inflow of the turbid water of Pahang River and Gumum River into Lake 1 (Sharip, pers. observation) could contribute to high $\mathrm{K}_{d}(\mathrm{PAR})$ in this lake during the high-water period which reduced light availability for submerged $C$. furcata. Mean turbidity in Lake $1(43.1 \pm 24.0 \mathrm{NTU})$ was significantly higher than Lake $12(5.2 \pm 3.6 \mathrm{NTU})$ $(\mathrm{p}<0.001)$. Higher mean turbidities above $30 \mathrm{NTU}$ in this lake were associated with flooding by the Pahang River [17].

In both lakes, phosphate concentrations were high in the littoral areas during low water level as compared with the pelagic zone (Fig. 7a and b). Phosphate concentration in both lakes increased with water level (Fig. 7c and d). The pattern of phosphate concentration in Lake 1 during the high water level shows that phosphate concentrations were higher at Station 3, which is along the deepest area of Lake 1 where the Gumum River flows (Fig. 7c). Gumum River, which provides the main outflow from the heavily agricultural catchment areas, could be the source for the high phosphate concentration in this lake. Higher phosphate concentration near the substrate in Lake 12 during high-water period could be due to nutrients release from sediments or mineralization of litters $[34,35]$. 


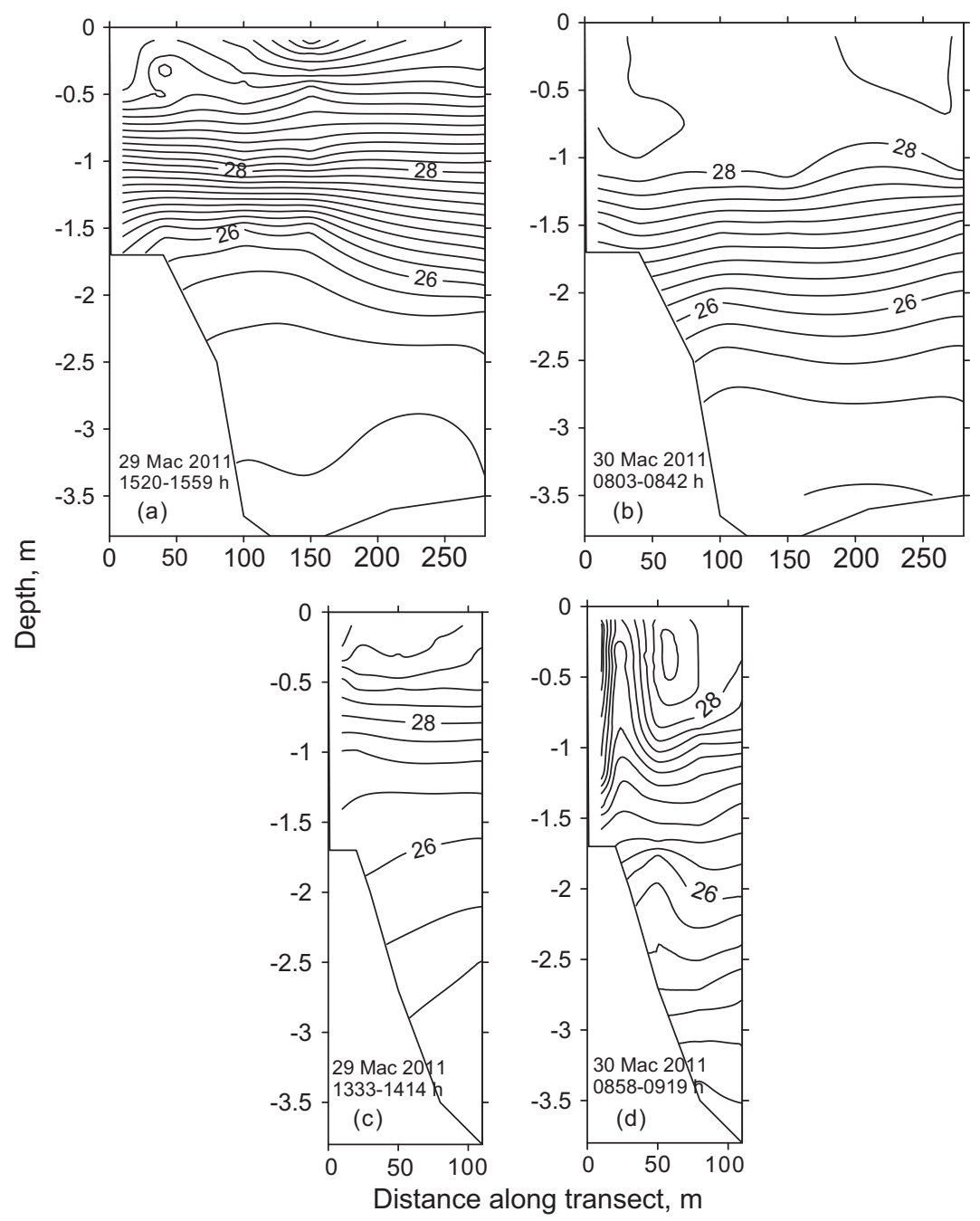

Figure 6: Longitudinal and vertical variations in water temperature in Lake 1 at around $1540 \mathrm{~h}$ on 29th March, at $0820 \mathrm{~h}$ on 30th March, and in Lake 12 at $1400 \mathrm{~h}$ on 29th March and at $0910 \mathrm{~h}$ on 30th March 2011.

\subsection{Heat budget and water exchange}

The boundary layer above the air-water interface was unstable $\left(\mathrm{zL}^{-1}<0\right)$ over the period of $20-23$ April 2010 (Fig. 8a and b) causing a higher transfer coefficient than neutral values (Fig. 8c and d). As transfer coefficients were a function of wind speed, drag $\left(\mathrm{C}_{\mathrm{D}}\right)$ and heat exchange $\left(\mathrm{C}_{\mathrm{H}}\right.$ and $\left.\mathrm{C}_{\mathrm{E}}\right)$ coefficients increased as wind increased and $\mathrm{z} / \mathrm{L}$ decreased, and, according to MacIntyre et al. [19], as exchange coefficient increase buoyancy effects became larger and tended to dominate. The hourly averages of the sensible heat fluxes were small compared with past studies in prairie wetlands [36] and ranged between $-41 \mathrm{~W} / \mathrm{m}^{2}$ and $4 \mathrm{~W} / \mathrm{m}^{2}$. Strong sensible heat fluxes (H) were found mostly in the early morning. Evaporative heat losses (E) were high during noon and late afternoon with a maximum value of $-270 \mathrm{~W} / \mathrm{m}^{2}$ in Lake 1 and $-208 \mathrm{~W} / \mathrm{m}^{2}$ in Lake 12 (Fig. 8e and f). 

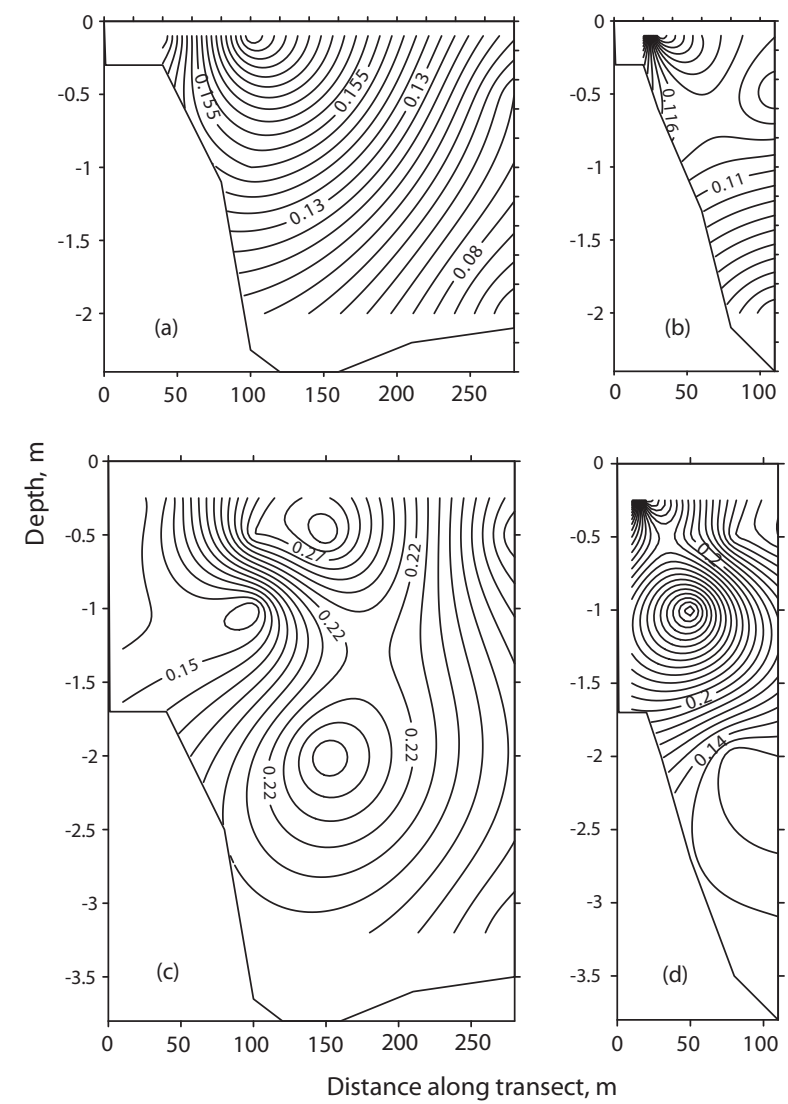

Figure 7: Longitudinal and vertical variations in phosphate concentration $(\mathrm{mg} / \mathrm{L})$ in (a) Lake 1 on 22nd April 2010, (b) Lake 12 on 22nd April 2010, (c) Lake 1 on 29th March 2011 and (d) Lake 12 on 29th March 2011.

Net radiation reached $790 \mathrm{~W} / \mathrm{m}^{2}$, and was an important heat flux that influences the heating and cooling of the water.

Using the method in Verburg et al. [21], where roughness lengths of momentum for smooth flow were used to parameterize the transfer coefficient for wind speed less than $5 \mathrm{~m} / \mathrm{s}$ [37], mean E were found to be lower by $9 \%$ in Lake 1 and $7.3 \%$ in Lake 12 while $\mathrm{H}$ was higher by $1.2 \%$ in Lake 1 and $3.8 \%$ in Lake 12 . As the solar energy from the incoming solar radiation during the day was still larger than these atmospheric surface fluxes, the stratification and horizontal density gradient were therefore primarily controlled by differential heating induced by solar insolation.

The water temperature distribution within the floating-leaved plant bed was based on the average temperature from the three sensors that spread along the transect in the littoral areas (Station 1). The horizontal temperature difference over the study period was more than $1^{\circ} \mathrm{C} / \mathrm{m}$ for $37 \%$ of the time during the day and $25 \%$ of the time during the night. This means the two areas could be recurrently circulated by the convective currents. We adopted a similar approach as in $[12,17,38]$ in estimating the lateral heat fluxes by simplifying that the exchange flow by differential heating occurs in the upper half of the water column and a return flow at the bottom. Correspondingly, the exchange flow by differential cooling was assumed to occur in the lower half of the water column with surface 

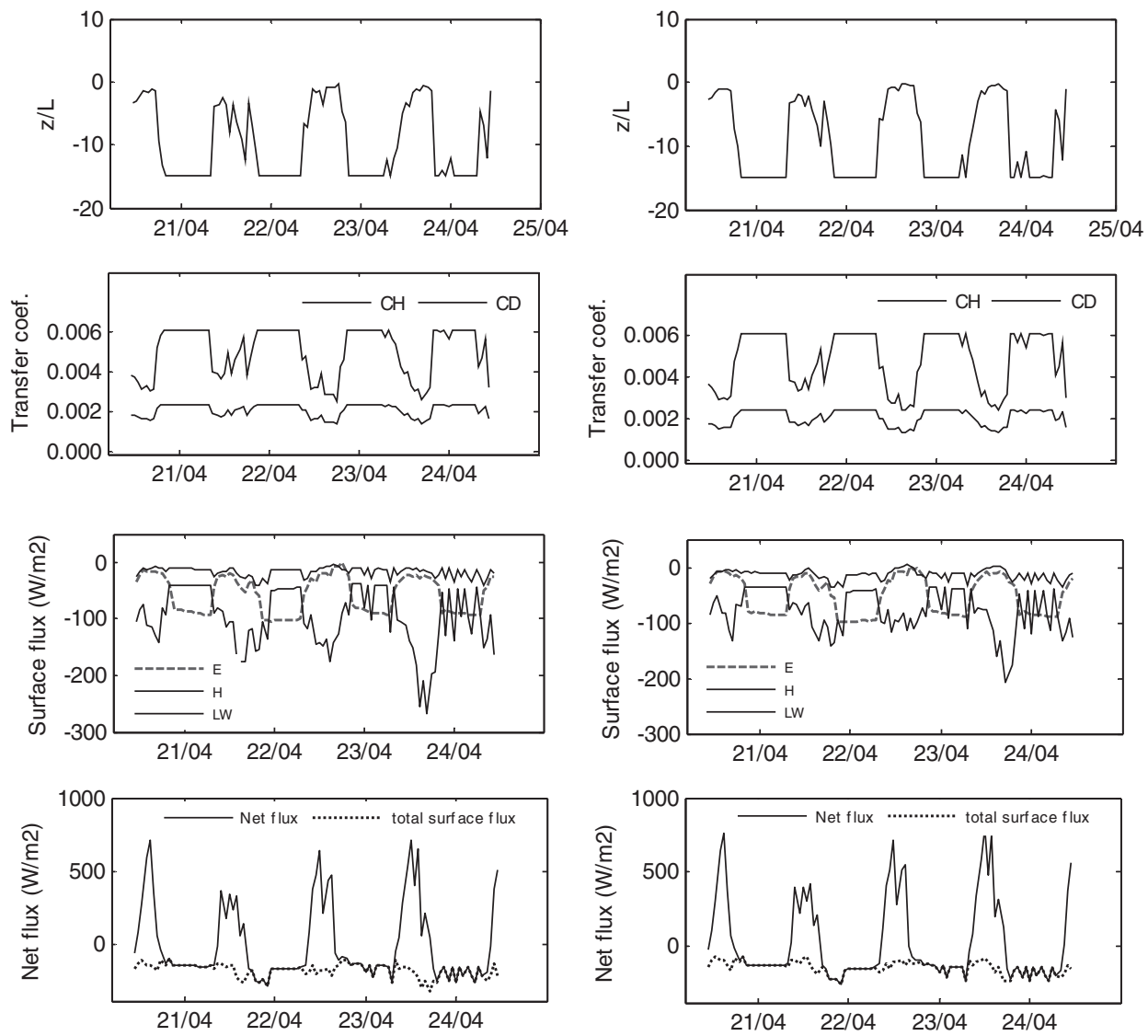

Figure 8: Air column stability, z/L in (a) Lake 1 and (b) Lake 12; Heat $\left(\mathrm{C}_{\mathrm{E}}\right)$ and momentum $\left(\mathrm{C}_{\mathrm{D}}\right)$ transfer coefficient corrected for atmospheric stability in (c) Lake 1 and (d) Lake 12; surface heat fluxes for the open water in (e) Lake 1 and (f) Lake 12. Surface heat flux components: sensible heat $(\mathrm{H})$, latent heat $(\mathrm{E})$ and net long wave radiation $(\mathrm{LW})$, and net heat fluxes in the open water in $(\mathrm{G})$ Lake 1 and $(\mathrm{H})$ Lake 12. Net heat fluxes components: total surface flux (sum of $\mathrm{E}, \mathrm{H}$ and $\mathrm{LW}$ ) and net heat flux.

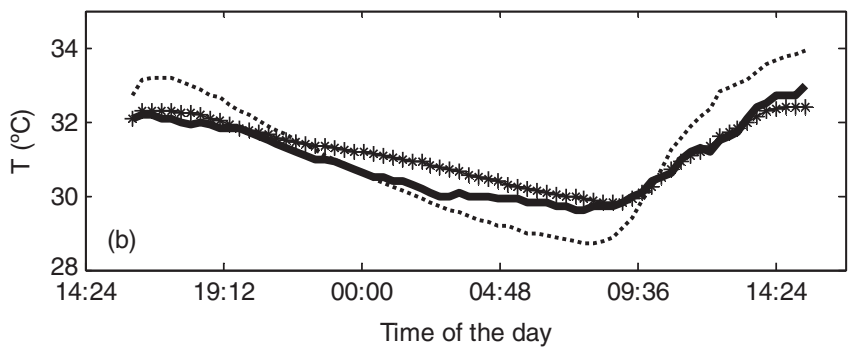

Figure 9: Measured temperature (solid line) and calculated temperature (star) at open water and littoral temperature (dotted line). 
return flow. The measured and calculated depth-averaged temperature (Fig. 9) indicates that the calculated temperature was reasonably predicted by the heat budget estimation, especially during the differential heating period $(\mathrm{p}<0.001)$. Wind speeds and atmospheric temperature were lowest during the night which led to a highly unstable boundary layer that could enhance the vertical transport and affect the estimation of the latent and sensible heat fluxes. The floating-leaved vegetation also affects the energy budget by altering the solar radiation penetration into the water by surface absorption during the day and lowers the evaporation heat loss from the surface water [21]. Correspondingly, the estimation of the latent heat fluxes has the largest uncertainties [12] as plant surfaces not only evaporate but also transpire depending on the vapor pressure of the surrounding [21]. The evapotranspiration over the plant surfaces depends on the physiological aspect of the species [39]. N. nucifera has a through-flow system which provides efficient transport of convective flow of gases [40] and subsequently complicates the calculation of the latent and sensible heat fluxes.

The water exchange between the littoral region covered by aquatic plants and the open water was derived from the lateral heat flux estimation, which is the heat difference between the surface heat fluxes and the measured temperature changes. Our results show the presence of a weak convective current due to differential heating and cooling between littoral and pelagic zones. The mean lateral heat fluxes were approximately $-155 \mathrm{~W} / \mathrm{m}^{2}$ and $160 \mathrm{~W} / \mathrm{m}^{2}$ during mid-afternoon and early morning respectively. This corresponds to a mean current of $1.6 \mathrm{~cm} / \mathrm{s}$ induced by differential heating between the floating-leaved $N$. nucifera stand and open water (Lake 1), and $1.9 \mathrm{~cm} / \mathrm{s}$ induced by differential cooling. This result is consistent with findings by Coates et al. [30], who found a weak thermally driven motion within the littoral zone induced by shading by the floating-leaved Nymphaea alba based on the measurement of the turbulence field within the vegetative littoral zone (VLZ). To confirm our estimation of the current flow, the horizontal velocity scale for the vertically mixed water column as described by Monismith et al. [4] was calculated, and the velocity of the convective current by differential heating was approximately $1.4 \mathrm{~cm} / \mathrm{s}$, which is close to the calculated velocity based on the surface energy budgets.

By estimating the hydraulic residence time $(\mathrm{t}=\mathrm{V} / \mathrm{Q})$ according to Stefan et al. [37], the results suggest that the mean areal convective flow induced by differential cooling and heating could exchange the whole volume of water within the floating-leaved bed in $1 \mathrm{~h}$ and $1.5 \mathrm{~h}$ respectively. In contrast to Lake 1, the convective current due to differential heating was smaller in Lake 12, with a mean velocity of $0.3 \mathrm{~cm} / \mathrm{s}$.

\section{DISCUSSION}

\subsection{Temperature structure and water exchange}

Strong temperature gradients were observed between the littoral and pelagic areas in this floodplain wetland and contributed to the convective circulation between the two zones. Surrounding topography and macrophyte abundance in the system influenced the onset and pattern of differential heating and cooling between lakes. Shading by riparian forest has been shown to reduce littoral temperature in boreal lakes [31], and the early onset of differential cooling at the littoral area of Lake 12 could be associated to the high-canopy forest surrounding the lakes causing early movement of cooler water towards the pelagic zone. Depth variation and shape of the lake contributed further to the pattern of differential heating and cooling, resulted in overflows from shallow littoral region to the pelagic zone during the day and movement of cooler littoral water as an underflow current into the deeper pelagic zone during the night $[1,4]$. Pattern of movement of cool water in this lake appears to be shaped by the presence of thick monospecific stands of a submerged macrophyte. Compared with the findings by Herb et al. [9], our study shows that the presence of dense submerged vegetation affects the circulation pattern induced by the horizontal density gradient. 
Stratifications were marked in both lakes during high water levels. In contrast to Lake 1, where stratification persisted at both littoral and pelagic zones by the morning period, a pattern of isothermy observed in Lake 12 at the littoral zone during a high water level could be induced by the shade from riparian forest. Few studies have shown the role of shape and surrounding topography in influencing lake stratification and mixing regime $[28,41]$ which could explain the thermal pattern in this wetland. Similar patterns of persistent thermal stratification have been documented in other floodplain lakes in the Amazon River during a high water level [28, 30, 42]. Marked differences of the light climate in Lake 1 during a high water level could be associated with increased turbidity in the water column, contributed largely from flooding by the turbid Pahang River [17]. Increased turbidity probably induces temperature stratification, where penetration of solar radiation is reduced to a smaller depth with a surface temperature rise as more heat is absorbed at the upper water column and the bottom temperature falls and becomes colder [25].

The estimated flow at the littoral zone was different between sites due to the different vegetation effects. Generally, floating-leaved species would alter the amount of radiation entering the water column by physically covering the water surface with their leaves [43]. The interception of the radiation would reduce the depth averaged temperature within the water column [12]. Higher littoral temperature within the floating leaved bed could be attributed to the low per cent cover by $N$. nucifera floating leaves over the surface water. In addition, $N$. nucifera stands have emergent leaves, with elongated stems shooting above the water, and this may affect the light climate. The presence of a dense monospecific $C$. furcata beds enhances daytime stratification in the water column as has been observed in past studies $[8,9]$. The plant leaves underneath the water surface may have prevented light penetrating deeper into the water column, causing cooler temperatures to develop relative to the pelagic zone [8]. Surface water above the macrophytes has higher temperature as a result of attenuated wind-driven mixing and interception of solar heating at the surface water [4, 8]. The water surface temperature between 0900 and $1800 \mathrm{~h}$ was on an average $2.5^{\circ} \mathrm{C}$ warmer in the littoral zone dominated by submerged species. Temperature gradients of more than $1^{\circ} \mathrm{C} / \mathrm{m}$ would give rise to density differences that can significantly reduce both vertical and horizontal mixing [38].

The horizontal density flow found in this work was within the rates of convective currents caused by differential heating and cooling as estimated in past studies; $1 \mathrm{~cm} / \mathrm{s}$ between open water and stands of Typha [13], 1.5-2.8 cm/s between open water and reed beds [11, 12], 3-5 cm/s between the wetland and lake [5], and $2-3.5 \mathrm{~cm} / \mathrm{s} \mathrm{[3]} \mathrm{and} 0.4-11 \mathrm{~cm} / \mathrm{s}$ [4] between shallower and deeper water. It should be emphasized that the estimation of the exchange flow in this study was based on MoninObukhov similarity theory which breaks down as wind speeds decrease to nearly wind-less free convection $[44,45]$ and this could have an effect on the night-time heat flux calculations. Some cautions are necessary while calculating the values of the estimated current induced by differential cooling as heat flux calculation during the night relies on latent and sensible heat fluxes under low wind conditions. Further study is necessary to estimate the heat flux under free convection within the floating-leaved stand using reliable wind speed measurement over the water-plant surface at the littoral zone and to determine the associated exchange flow between vegetated and open water during cooling period.

\subsection{Implications of physical-chemical coupling to macrophyte dynamics}

The induced horizontal density gradient could improve transport of phosphate from the littoral area to other areas in the pelagic zones. The circulation pattern provides a better spread of nutrients for the growth of submerged macrophytes within the area. As Cabomba populations can uptake nutrients through stems and shoots [15], the improved nutrient delivery to submerged macrophyte bed in other areas by horizontal transport may promote the proliferation of submerged $C$. furcata in the 
wetland. The undercurrent may transport nutrients to submerged $C$. furcata that grow in deeper pelagic areas [14] during the night and early morning, and the available resource could be used by the plant for photosynthesis during the day for its growth, increasing its abundance.

Additionally, the increase in water column turbidity and thermal stratification in this wetland, in particular, during the flooding by the main river could lead to anoxic conditions and subsequently an increase in nutrients. Pattern of persistent thermal stratification in other floodplain lakes during a high water level caused anoxia [42] and elevated concentrations of nutrients [31]. High phosphate concentrations in the two lakes during a high water level were attributed by different sources of nutrient with run-off from agriculture area [17] that flows into the nearby river and mineralization of the dominant submerged plant litters $[34,35]$ possibly explains the elevated phosphate level in Lake 1 and Lake 12 respectively. The availability of nutrients in the lake after flooding could contribute further to the elevated abundance of submerged macrophytes in the system [14]. The thermal structure in floodplain lakes during low- and high water levels affects the oxygen and nutrient dynamics in the water column [4, 42], which could be an important factor shaping the productivity in the wetland system. Further study should investigate the oxygen dynamic, which is influenced by the temperature structure as shown by numerous studies [31, 42], and how it relates to production by the macrophyte in this wetland.

\section{CONCLUSIONS}

This study documents the contribution of aquatic vegetation to thermal structure and water exchange dynamics. The horizontal density gradient may also be affected by rooted floating-leaved vegetation and submerged vegetation. Floating-leaved vegetation creates shading and alters the light condition that could induce convective motion while submerged vegetation affects the light and temperature pattern by reducing light penetration, increasing stratification and altering the circulation pattern which affects the water quality in the lakes. A rise in the water level altered the thermal gradient and the exchange dynamics and mixing in the lake system and the variation in physical characteristics of the lake affected the temperature and convective circulation.

The horizontal density gradient and water exchange have important implications for nutrient cycling in this shallow lake system. A change of macrophyte dominance from floating-leaved to submerged macrophyte affects the physical circulation and exchange flow and contributes towards improved delivery of constituents such as phosphate and other nutrients to $C$. furcata beds. The increased availability of resources could further promote growth of this submerged species and subsequently contributes to invasion in the wetland system. The findings from this study have implications for the rehabilitation and management of the wetland.

\section{ACKNOWLEDGEMENTS}

The first author gratefully acknowledges the support from National Hydraulic Research Institute of Malaysia (NAHRIM) for permission to use their data and provision of financial assistance for the field experiments. Thanks to Ahmad Taqiyuddin Ahmad Zaki for his assistance and coordination during all field surveys and Justin Brookes for provision of sensors and assistance during April field experiment. An anonymous reviewer contributed helpful comments.

\section{REFERENCES}

[1] Horsch, G.M. \& Stefan, H.G., Convective circulation in littoral water due to surface cooling. Limnology and Oceanography, 33, pp. 1068-1083, 1988. doi: http://dx.doi.org/10.4319/ $\underline{\text { lo.1988.33.5.1068 }}$

[2] James, W.F. \& Barko, J.W., Littoral-pelagic phosphorus dynamics during nighttime convective circulation. Limnology and Oceanography, 36, pp. 949-960, 1991. doi: http://dx.doi. org/10.4319/lo.1991.36.5.0949 
[3] Palmarsson, S.O. \& Schladow, S.G., Exchange flow in a shallow lake embayment. Ecological Applications, 18, pp. A89-A106, 2008. doi: http://dx.doi.org/10.1890/06-1618.1

[4] Monismith, S.G., Imberger, J. \& Morison, M.L., Convective motions in the sidearm of a small reservoir. Limnology and Oceanography, 35, pp. 1676-1702, 1990. doi: http://dx.doi. org/10.4319/lo.1990.35.8.1676

[5] Nepf, H.M. \& Oldham, C.E., Exchange dynamics of a shallow contaminated wetland. Aquatic Sciences, 59, pp. 193-213, 1997. doi: http://dx.doi.org/10.1007/BF02523273

[6] MacIntyre, S. \& Melack, J.M., Vertical and horizontal transport in lakes: linking littoral, benthic, and pelagic habitats. Journal of the North American Benthological Society, 14, pp. 599-615, 1995. doi: http://dx.doi.org/10.2307/1467544

[7] Dale, H.M. \& Gillespie, T.J., Diurnal fluctuations of temperature near bottom of shallow-water bodies as affected by solar-radiation, bottom color and water circulation. Hydrobiologia, 55, pp. 87-92, 1977. doi: http://dx.doi.org/10.1007/BF00034810

[8] Coates, M.J. \& Ferris, J., The radiatively driven natural convection beneath a floating plant layer. Limnology and Oceanography, 39, pp. 1186-1194, 1994. doi: http://dx.doi.org/10.4319/ $\underline{\text { lo.1994.39.5.1186 }}$

[9] Dale, H.M. \& Gillespie, T.J., The influence of submerged plants on temperature gradients in shallow water bodies. Canadian Journal of Botany, 55, pp. 2216-2225, 1977. doi: http:// dx.doi.org/10.1139/b77-251

[10] Herb, W.R. \& Stefan, H.G., Temperature stratification and mixing dynamics in a shallow lake with submersed macrophytes. Lake and Reservoir Management, 20, pp. 296-308, 2004. doi: http://dx.doi.org/10.1080/07438140409354159

[11] Lovstedt, C.B., Thermally-driven currents induced by shading from emergent reed vegetation. Proc. of the $30^{\text {th }}$ Congress of the International Association of Theoretical and Applied Limnology, Stuttgart, pp. 528-530, 2008. doi: http://dx.doi.org/10.1029/2008WR006949

[12] Lovstedt, C.B. \& Bengtsson, L., Density-driven current between reed belts and open water in a shallow lake. Water Resources Research, 44, W10413, doi:10.1029/2008WR006949, 2008.

[13] Waters, M.T., Effects Of Vegetation On The Hydrodynamics Of Freshwater Wetlands, University of New South Wales, p. 267, 1998.

[14] Sharip, Z., Schooler, S.S., Hipsey, M.R. \& Hobbs, R.J., Eutrophication, agriculture and water level control shift aquatic plant communities from floating-leaved to submerged macrophytes in Lake Chini, Malaysia. Biological Invasions, doi:10.1007/s10530-011-0137-1, 2011. doi: http://dx.doi.org/10.1007/s10530-011-0137-1

[15] Wilson, C.E., Darbyshire, S.J. \& Jones, R., The biology of invasive alien plants in Canada. 7. Cabomba caroliniana A. Gray. Canadian Journal of Plant Science, 87, pp. 615-638, 2007. doi: http://dx.doi.org/10.4141/P06-068

[16] Sharip, Z. \& Jusoh, J., Integrated lake basin management and its importance for Lake Chini and other lakes in Malaysia. Lakes \& Reservoirs: Research \& Management, 15, pp. 41-51, 2010. doi: http://dx.doi.org/10.1111/j.1440-1770.2010.00421.x

[17] Shuhaimi-Othman, M., Lim, E.C. \& Mushrifah, I., Water quality changes in Chini Lake, Pahang, West Malaysia. Environmental Monitoring and Assessment, 131, pp. 279-292, 2007. doi: http://dx.doi.org/10.1007/s10661-006-9475-3

[18] Smith, C.S., James, W.F., Barko, J.W. \& Eakin, H.L., Studies Of Water Movement In Vegetated And Unvegetated Littoral Areas, U.S. Army Engineer Waterways Experiment Station: Vicksburg, pp. 13-25, 1995.

[19] MacIntyre, S., Romero, J.R. \& Kling, G.W., Spatial-temporal variability in surface layer deepening and lateral advection in an embayment of Lake Victoria, East Africa. Limnology and Oceanography, 47(3), pp. 656-671, 2002. doi: http://dx.doi.org/10.4319/1o.2002.47.3.0656 
[20] Tennessee Valley Authority, Heat and mass transfer between a water Surface and the Atmosphere. Water Resource Research Laboratory Report, 14, Tennessee Valley Authority: Tennessee, pp. 176, 1972.

[21] Verburg, P. \& Antenucci, J.P., Persistent unstable atmospheric boundary layer enhances sensible and latent heat loss in a tropical great lake: Lake Tangayika. Journal of Geophysical Research, 115, D11109, doi:10.1029/2009JD012839, 2010.

[22] Shaw, E.M., Hydrology in Practice, Chapman \& Hall: London, 1994.

[23] Cooley, K.R. \& Idso, S.B., Effects of lily pads on evaporation. Water Resources Research, 16(3), pp. 605-606, 1980. doi: http://dx.doi.org/10.1029/WR016i003p00605

[24] Amorocho, J. \& DeVries, J.J., A new evaluation of the wind stress coefficient over water surfaces. Journal of Geophysical Research, 85, pp. 433-442, 1980. doi: http://dx.doi.org/10.1029/ JC085iC01p00433

[25] Imberger J. \& Patterson J.C., Physical limnology. Advances in Applied Mechanics, eds J.W. Hutchinson \& T.Y. Wu, Academic Press: San Diego, 27, pp. 303-475, 1990.

[26] Kirk, J.T.O., Light And Photosynthesis In Aquatic Ecosystems, Cambridge University Press: Cambridge, 1983.

[27] Ganf, G., Diurnal mixing and vertical distribution of phytoplankton in a shallow equatorial lake (Lake George, Uganda). Journal of Ecology, 62, pp. 611-629, 1974. doi: http://dx.doi. org $/ 10.2307 / 2259002$

[28] MacIntyre, S. \& Melack, J.M., Vertical mixing in Amazon floodplain lakes. Verhandlungen des Internationalen Verein Limnologie, 22, pp. 1283-1287, 1984.

[29] Furtado, J.I. \& Mori, S., The Ecology Of A Tropical Freshwater Swamp, The Tasek Bera, Malaysia, Dr W. Junk Publishers: The Hague, 1982.

[30] Coates, M.J. \& Folkard, A., The effects of littoral zone vegetation on turbulent mixing in lakes. Ecological Modelling, 220, pp. 2714-2726, 2009. doi: http://dx.doi.org/10.1016/j.ecolmodel.2009.06.042

[31] MacIntyre, S. \& Melack, J.M., Frequency and depth of vertical mixing in an amazon floodplain (L. Calado, Brazil). Verhandlungen des Internationalen Verein Limnologie, 23, pp. 80-85, 1988.

[32] Steedman, R.J., France, R.L., Kushneriuk, R.S. \& Peters, R.H., Effects of riparian deforestation on littoral water temperatures in small Boreal forest lakes. Boreal Environment Research, 3, pp. 161-169, 1998.

[33] Folkard, A.M., Temperature structure and turbulent mixing processes in Cumbrian lakes. North West Geography, 8(1), pp. 42-50, 2008.

[34] Shilla, D., Asaeda, T., Fujino, T. \& Sanderson, B., Decomposition of dominant submerged macrophytes: implications for nutrient release in Myall Lake, NSW, Australia. Wetlands Ecology and Management, 14, pp. 427-433, 2006. doi: http://dx.doi.org/10.1007/s11273-006-6294-9

[35] Carpenter, S.R. Enrichment of Lake-Wingra, Wisconsin, by submersed macrophyte decay. Ecology, 61, pp. 1145-1155, 1980. doi: http://dx.doi.org/10.2307/1936834

[36] Burba, G.G., Verma, S.B. \& Kim, J., Energy fluxes of an open water area in a mid-latitude prairie wetland. Boundary-Layer Meteorology, 91, pp. 495-504, 1999. doi: http://dx.doi. org/10.1023/A:1001802821846

[37] Smith, S.D., Coefficients for sea-surface wind stress, heat-flux, and wind profiles as a function of wind-speed and temperature. Journal of Geophysical Research-Oceans, 93, pp. 15467-15472, 1988. doi: http://dx.doi.org/10.1029/JC093iC12p15467 
[38] Stefan, H.G., Horsch, G.M. \& Barko, J.W., A model for the estimation of convective exchange in the littoral region of a shallow lake during cooling. Hydrobiologia, 174, pp. 225-234, 1989. doi: http://dx.doi.org/10.1007/BF00008162

[39] Lafleur, P. Evaporation from wetlands. Canadian Geographer, 34, pp. 79-82, 1990. doi: http:// dx.doi.org/10.1111/j.1541-0064.1990.tb01072.x

[40] Konnerup, D., Sorrell, B.K. \& Brix, H., Do tropical wetland plants possess convective gas flow mechanisms? New Phytologist, 190, pp. 379-386, 2011. doi: http://dx.doi.org/10.1111/j.1469$\underline{8137.2010 .03585 . \mathrm{x}}$

[41] Melack, J.M., Amazon floodplain lakes: shape, fetch and stratification. Verhandlungen des Internationalen Verein Limnologie, 22, pp. 1278-1282, 1984.

[42] Melack, J. \& Fisher, T., Diel oxygen variations and their ecological implications in Amazon floodpain lakes. Archiv Fur Hydrobiologie, 98, pp. 422-442, 1983.

[43] Folkard, A.M. \& Coates, M.J., Flow in wetlands and macrophyte beds. Biogeochemistry of inland waters: A derivative of encyclopedia of inland waters, ed G.E. Likens, Millbrook: Academic Press, pp. 301-312, 2010.

[44] Deardorf, J.W., Parameterization of planetary boundary-layer for use in general circulations models. Monthly Weather Review, 100, pp. 93-106, 1972. doi: http://dx.doi.org/10.1175/15200493(1972)100<0093:POTPBL $>2.3$. CO;2

[45] Beljaars, A., The parameterization of surface fluxes in large-scale models under free-convection. Quarterly Journal of the Royal Meteorological Society, 121, pp. 255-270, 1995. doi: http://dx.doi.org/10.1002/qj.49712152203 